\title{
Prospective Evaluation of Laparoscopy in Management of Infantile Intussusception
}

\author{
MAGED E. KHAIRALLAH, M.Sc.; HAMED M. SELEIM, M.D.; MOHAMED I. EL-SAWAF, M.D. and \\ KHALED A. ISMAIL, M.D.
}

The Department of Pediatric Surgery, Faculty of Medicine, Tanta University

\begin{abstract}
Background: Laparoscopy was initially utilized as a diagnostic tool for failed reduction of intussusception and then was tried as an aid to hydrostatic reduction and recently laparoscopy is used as a definitive treatment.
\end{abstract}

Aim of Study: In this study we are trying to evaluate the role of laparoscopy in management of infantile intussusception.

Patients and Methods: This prospective study was conducted on 58 childern suffering from intussusception, admitted to the Pediatric Surgery Unit of Tanta University Hospital from June 2017 to June 2018.

Results: Our study included 58 patients with intussusception with a mean age of 10.95 months. $32(55.2 \%)$ presented early with mild symptoms, $38(65.5 \%)$ showed red currant jelly stool, 37 (63.8\%) presented with intestinal obstruction, and $3(5.2 \%)$ showed signs of peritonitis. Mass was subhepatic in 33 infants $(56.9 \%)$. Hydrostatic reduction was attempted in stable cases (55) and 3 cases with peritonitis underwent immediate laparotomy. Of 55 cases, 39 (71\%) were successfully managed using hydrostatic reduction. Laparoscopic reduction was attempted in $16(29 \%)$ cases, $12(75 \%)$ were completed laparoscopically and $4(25 \%)$ cases were converted to laparotomy, one reduced manually and 3 cases had bowel resection. Operative time ranged between 30-180 with a mean of 83.95 minutes. Mean hospital stay was 1.8 days. One case had port site hernia (1.7\%) and there was no recurrence detected in any case. Follow-up ranged between 1-12 months.

Conclusion: Laparoscopic reduction of idiopathic intussusception is safe, feasible and provides minimally invasive approach with significantly early oral feeding and reduced hospital stay.

Key Words: Laparoscopic - Intussusception - Hydrostatic reduction.

\section{Introduction}

INTUSSUSCEPTION is one of the main abdominal emergencies in children. It is the single most common cause of small bowel obstruction in chil-

Correspondence to: Dr. Maged E. Khairallah, The Department of Pediatric Surgery, Faculty of Medicine, Tanta Universit dren younger than 5 years [1]. Its diagnosis is usually based on clinical features and is confirmed either by Ultrasonography (U/S) or contrast enema, Computed Tomography (CT) scan is considered in rare occasions [2]. Since the introduction of hydrostatic reduction by Ravitch in 1848, it became the gold standard for management of intussusception [3] . Radiological reduction of intussusception (air or saline enema) is considered the first-line of treatment with an average success rate $80 \%$ (range 40\%-90\%) [4] . Surgical intervention is required for the cases with failed enema reduction, hemodynamic instability and/or peritonitis. This typically involves 10 to $20 \%$ of cases [5].

Early, the approach has been through open laparotomy and manual reduction of intussusception. Laparotomy increases postoperative pain, leads to a less desirable cosmetic result and higher risk of post-operative adhesive small bowel obstruction [6]. Later, introduction of laparoscopy in pediatric surgical field has added another dimension to the management of intussusception. The use of laparoscopy has increased significantly in the past 20 years [7]. It was initially utilized as a diagnostic modality after failed hydrostatic reduction of intussusception and then was tried as an aid to hydrostatic reduction (laparoscopic-assisted hydrostatic reduction) followed by using laparoscopy as a definitive treatment. In addition, it can resect the pathological lead point or the damaged segment of bowel in some cases [8,9].

Although some articles show an advantage of the laparoscopic over the open approach, complications such as serosal tearing and frank perforation have been reported [8].

Although the agreed benefits of less pain, better cosmesis, shorter operative time, shorter time to 
full feeds, low long-term risk of adhesive bowel obstruction and significantly reduced length of hospital stay as compared to open surgery regardless of primary pathology [10,11], there is a possible pitfall of the laparoscopic technique which is loss of tactile sensation to rule out the presence of pathologic leadpoint. Despite of the mentioned advantages of laparoscopy, its feasibility has been questioned [12,13]

\section{Patients and Methods}

This case series was carried out in the Pediatric Surgical Unit, Tanta University Hospital, during the period from June 2017 to June 2018, on 58 patients with infantile idiopathic intussusception. The study was approved by Ethical Committee of the Faculty of Medicine, Tanta University (Approval Code 3 1575/05/17). A written informed consent was taken from the parents. The procedure was explained in details and in a clear simple language. All possible complications were explained. We included all patients with infantile idiopathic intussusception less than two years after failure of non-operative treatment with hydrostatic reduction. The exclusion criteria included neglected patients with toxemia and bad general condition not allowing laparoscopic intervention, previous abdominal surgery, known primary disease e.g. lymphoma and major congenital anomalies that may affect the outcome. All patients were subjected to full clinical evaluation and laboratory investigations as needed. Abdominal U/S was done to confirm the presence of bowel mass.

\section{Operative techniques:}

All patients received general anesthesia with endotracheal intubation in a supine position, near the edge of the table the surgeon stood at the patient's left side. However he may rotate to the right or the left of the table depending on the position of the intussusception. The camera man was standing beside the surgeon at the left side of the patients while the scrub nurse at the foot of the table, the anaesthesist wasstanding at the head of patient and laparoscope tower at the right side in front of the surgeon.

In all patients, an open technique was used to establish pneumoperitoneum at the site of umbilical port. The abdomen was insufflated with $\mathrm{CO}_{2}$, initially at $6-8 \mathrm{mmHg}$ pressure, with a flow of 1.5 $\mathrm{L} / \mathrm{min}$. Pressure was then raised to $8-12 \mathrm{mmHg}$ and flow to $2-3 \mathrm{~L} / \mathrm{min}$ depending on age. Two other 3 or $5 \mathrm{~mm}$ working ports for manipulation were placed depending on the position of the mass and size of the patient either in the suprapubic area (midline) and the left upper quadrant or both the upper left and lower left quadrants of the abdomen.

This port position is assuming that radiological reduction has carried the intussusceptum to the hepatic flexure. The head of the table was lowered in Trendelenburg's position and the right side is up to keep viscera away from the site of intussusception. Laparoscopy was used firstly for routine exploration of abdomen in all patients and identification of bowel mass.

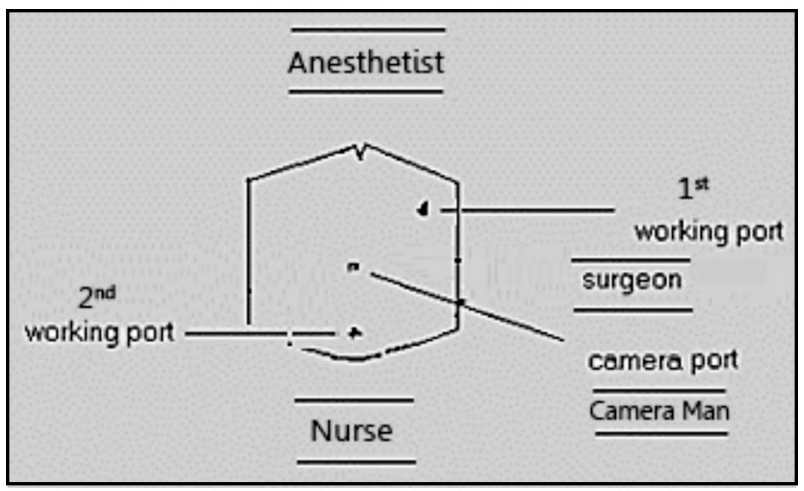

Fig. (1): Trocars position in intussusception reduction.

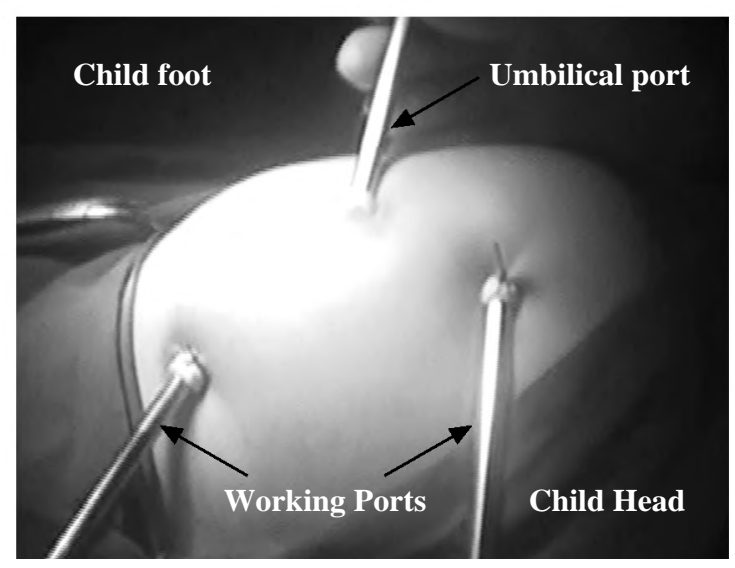

Fig. (2): Ports position.

- Two atraumatic bowel graspers were used for bowel manipulation. Many tricks for reduction were used as:

a- Gentle traction of the proximal segment (intussusceptum) from the distal segment (intussuscipiens).

b- Milking of the intussusceptum from the distal bowel.

c- Irrigation with warm saline to decrease bowel odema and help reduction.

- Alternating between the previous 3 steps was usually made until complete reduction is achieved.

- Gentle manipulation was done recquired to avoid injury to the bowel. 
- Inspection of the bowel to assure complete reduction and absence of PLP was done before ending the procedure.

- After complete reduction, deflation of the abdomen and closure of $5 \mathrm{~mm}$ port sites was done.

- In case of failed reduction or there was no progress for 30min. to one hour, conversion to laparotomy was done and simple manual reduction was tried.

\section{Post-operative care:}

- All patients were transferred to recovery area then to the wards and received iv generation cephalosporin $100 \mathrm{mg} / \mathrm{kg} /$ dose, metronidazole 7.5 $\mathrm{mg} / \mathrm{kg} / \mathrm{dose}, \mathrm{I} . \mathrm{V}$ paracetamol $(7.5 \mathrm{mg} / \mathrm{kg} / \mathrm{dose})$ as post-operative analgesia in 1 st 24 hours following procedure.

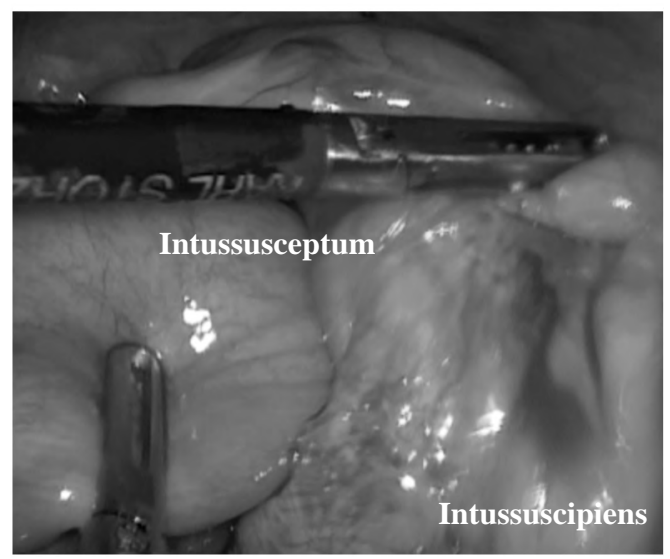

Fig. (3): Traction of the proximal intussusceptum out of the distal intussuscipiens.

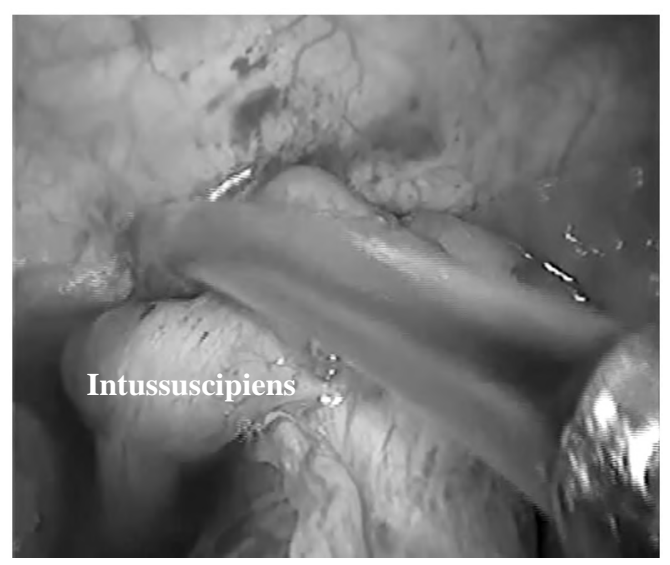

Fig. (5): Irrigation with warm saline at the site of intussusception.

\section{Results}

Our study included 58 patients with intussusception with a mean age of 10.95 months. 32 $(55.2 \%)$ presented early with mild symptoms, 38 $(65.5 \%)$ showed red currant jelly stool, 37 (63.8\%)
- Oral fluids were started 6 hours after procedure and semi-solids or milk were started as the patient tolerated.

- All patients were discharged after 48 hours after reaching full feeds unless otherwise indicated.

- Follow-up by u/s before discharge to detect recurrence if occurred.

- Discharge medications (oral antibiotic as linezolide $100 \mathrm{mg}$ suspension according to weight, oral paracetamol on demand).

\section{Follow-up:}

- All patients were seen one week after the surgery at the outpatient clinic where wounds were examined for evidence of wound infection or hernia.

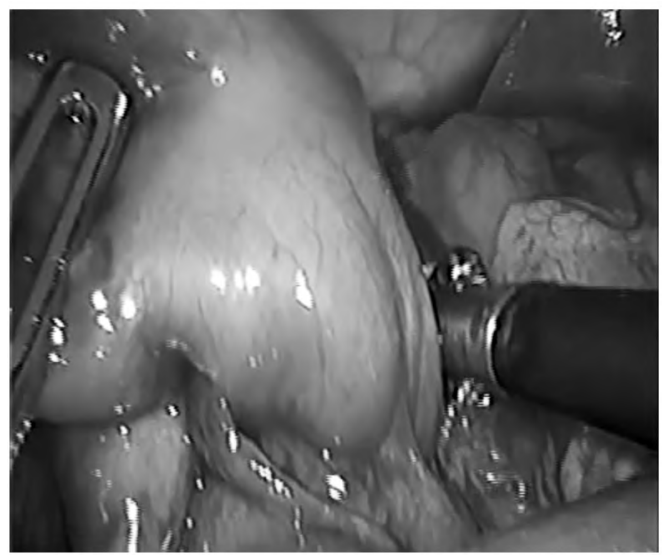

Fig. (4): Milking of the intussusceptum from the distal bowel.

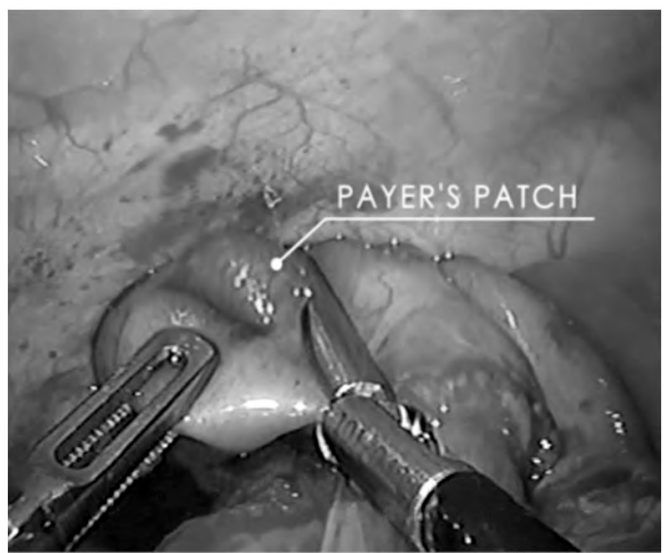

Fig. (6): After complete reduction of ileocolic intussusception.

presented with intestinal obstruction, and 3 (5.2\%) showed signs of peritonitis. Mass was sub-hepatic in 33 infants $(56.9 \%)$. Hydrostatic reduction was attempted in stable cases (55) and 3 cases with peritonitis underwent immediate laparotomy. Of 55 cases, 39 (71\%) were successfully managed 
using hydrostatic reduction. Laparoscopic reduction was attempted in $16(29 \%)$ cases, $12(75 \%)$ were completed laparoscopically and $4(25 \%)$ cases were converted to laparotomy, one was reduced manually and 3 cases had bowel resection. Operative time ranged between 30-180 with a mean of 83.95 minutes. Mean hospital stay was 1.8 days. One case had port site hernia $(1.7 \%)$ and there was no recurrence detected in any case. Follow-up ranged between 1-12 months.
We found no correlation between age and weight of patients and the success of hydrostatic or laparoscopic reduction, while duration of symptoms significantly affected success of reduction either when using hydrostatic enema or laparoscopic reduction.

Also, we found significantly early tolerance to oral feeding and shorter hospital stay in favor of patients reduced laparoscopically.

Table (1): Comparison between different modalities of intervention in our study.

\begin{tabular}{|c|c|c|c|c|c|c|c|}
\hline & \multirow{3}{*}{$\begin{array}{c}\text { Total } \\
(\mathrm{n}=58)\end{array}$} & \multirow{3}{*}{$\begin{array}{l}\text { Hydrostatic } \\
\text { reduction } \\
\quad(n=39)\end{array}$} & \multirow{3}{*}{$\begin{array}{l}\text { Laparotomy } \\
\qquad(\mathrm{n}=3)\end{array}$} & \multicolumn{3}{|c|}{ Laparoscopic intervention $(n=16)$} & \multirow{3}{*}{$\begin{array}{c}p- \\
\text { value }\end{array}$} \\
\hline & & & & \multirow{2}{*}{$\begin{array}{l}\text { Successful } \\
\qquad(\mathrm{n}=12)\end{array}$} & \multicolumn{2}{|c|}{$\begin{array}{l}\text { Conversion to open } \\
\text { approach }(n=4)\end{array}$} & \\
\hline & & & & & $\begin{array}{l}\text { Reduction } \\
\quad(n=1)\end{array}$ & $\begin{array}{l}\text { Resection } \\
\quad(n=3)\end{array}$ & \\
\hline Age (month) & $10.94 \pm 5.22$ & $9.69 \pm 3.88$ & $15.67 \pm 6.66$ & $12.50 \pm 6.50$ & 10 & $16.67 \pm 9.29$ & $0.045 *$ \\
\hline Weight (Kg) & $8.90 \pm 1.69$ & $8.62 \pm 1.66$ & $10.33 \pm 0.58$ & $9.42 \pm 1.83$ & 9 & $9.00 \pm 2.00$ & 0.364 \\
\hline Time of Complaint (hour) & $21.60 \pm 10.09$ & $20.38 \pm 8.33$ & $40.67 \pm 6.43$ & $21.33 \pm 11.36$ & 6 & $24.67 \pm 11.02$ & $0.004 *$ \\
\hline Procedure time (min.) & $83.95 \pm 46.27$ & $3-10$ & $135.00 \pm 15.00$ & $55.83 \pm 18.81$ & 120 & $133.33 \pm 64.29$ & $0.001 *$ \\
\hline Oral feeding (hour) & $11.90 \pm 12.84$ & $8.77 \pm 8.90$ & $40.00 \pm 6.93$ & $7.50 \pm 2.71$ & 48 & $30.00 \pm 21.63$ & $0.001 *$ \\
\hline Hospital stay (day) & $1.80 \pm 1.11$ & $1.56 \pm 1.08$ & $3.33 \pm 0.58$ & $1.64 \pm 0.50$ & 4 & $2.67 \pm 1.53$ & $0.006^{*}$ \\
\hline Post-operative complication (\%) & $5(8.6 \%)$ & $0(0 \%)$ & $2(66.7 \%)$ & $1(8.3 \%)$ & $0(0 \%)$ & $2(66.7 \%)$ & $0.001 *$ \\
\hline Recurrence $(\%)$ & & $0(0 \%)$ & $0(0 \%)$ & $0(0 \%)$ & $0(0 \%)$ & $0(0 \%)$ & \\
\hline Mortality (\%) & & $0(0 \%)$ & $0(0 \%)$ & $0(0 \%)$ & $0(0 \%)$ & $0(0 \%)$ & \\
\hline
\end{tabular}

\section{Discussion}

Infantile intussusception is a common pediatric problem and a potentially life-threatening cause of bowel obstruction in children [2]. Enema reduction is the first line of treatment with high rate of success. Daneman et al., reported $85 \%$ success rate for pneumatic reduction of intussusception $[14,15]$

When non operative reduction fails or if there is a clinical evidence of bowel ischemia or peritonitis, operative intervention becomes necessary. There is a controversy regarding the optimal operative approach (laparotomy vs. laparoscopy) recommended for treatment of intussusception.

Conventional laparotomy was considered the standard approach. However, over the last two decades, advances in minimally invasive surgery were reflected into the management of infantile intussusception. With the improvement of surgeon's laparoscopic skills and instruments, laparoscopic reduction may be attempted without a significant increase in mortality or morbidity [16]. The reported advantages of laparoscopy over the conventional procedure were short operative time, better postoperative pain control, low long-term risk of adhesive bowel obstruction, significantly shorter number of days to tolerating full feeds, significantly reduced hospital stay and desirable cosmetic results $[\mathbf{1 0 , 1 1 ]}$
In the present study, we attempted to document the role of laparoscopy in management of sases infantile idiopathic intussusception not reduced by saline enema.

Our study included 58 patients presenting with idiopathic intussusception. Thirty nine children (71\%) were successfully reduced by saline enema. The age ranged from 4 to 23 months with mean age $(10.95 \pm 5.22)$ months and the weight ranged from 6 to $13 \mathrm{~kg}$ with mean weight $(8.90 \pm 1.69) \mathrm{kg}$. Three children $(5 \%)$ presented with peritonitis and were treated by laparotomy from the start. Sixteen children (29\%) were managed laparoscopically, twelve were being successfully reduced $(75 \%)$. The other four children were converted to laparotomy due to failed laparoscopic reduction.

In 2013, Apelt et al., [17] in a systematic review of all publications on the laparoscopic treatment of pediatric intussusception from January 1990 to April 2012, he reported that among total number of 276 patients who have been treated laparoscopically, the success rate was more than $70 \%$ with a low rate of intraoperative $(0.4 \%)$ and post-operative complication (2.9\%) while in a study of Hill et al., in 2013 [7] of 92 patients treated for intussusception, laparoscopic reduction was attempted in $70 \%(\mathrm{n}=$ $65)$ and was successful in $68 \%$ of the time $(n=44)$. 
The duration between the onset of symptoms and presentation to our service is closely related to the outcome; the shorter the duration, the better the outcome. In our study the mean duration noted to be significantly longer in cases that were initially managed by laparotomy ( $40.67 \pm 6.43 \mathrm{~h})$ and was significantly short in cases successfully managed laparoscopically $(21.33 \pm 11.36)$ and in the cases that were reduced by hydrostatic enema $(20.38 \pm$ 8.33).

In a multi-center retrospective study conducted between 1992 and 2005, the French study group for pediatric laparoscopy (GECI) reported similar results and showed that after failed hydrostatic enema reduction, the best candidates for laparoscopic management were those patients with short lag time between onset of symptoms to intervention ( $<1.5$ days $)$, and in whom there were no signs of peritonitis [19]

During laparoscopic intervention we used as many tricks as we use in open surgery (traction and counter traction, milking of intussusceptum, irrigation with warm saline or mix of all of above). The only drawback of laparoscopy is loss of tactile perception of PLP and use of instruments instead of our hands (much more fine) which may lead to serosal tears and bowel injury, but we still find that it is feasible in the presence of enough experience and patience.

The operative mean time in the current study was calculated from skin incision to skin closure, and it was $(55.83 \pm 18.81)$ minutes in the cases that were successfully completed laparoscopically. It was noted to be significantly longer $(135.00 \pm 15.00)$ minutes in cases that were managed by laparotomy from the start.

In contrast to our study, Wie et al., in 2015 [20] reported 23 and 35 patients in laparoscopic and laparotomy group, respectively. The mean operative time was significantly longer in LAP group (70.4 \pm 37.7 vs. $47.3 \pm 15.1 \mathrm{~min}, p=0.01$ ) in laparotomy group due to early use of laparoscopy and little experience.

On the other hand, Hill et al., [7] in 2013 in a study of 92 patients treated for intussusception (65 in LAP group and 27 in the OPEN group), the operative time was shorter in LAP group $(50.3 \pm$ $35.1)$ minutes than the OPEN group $(65.78 \pm 29.1)$ minutes.

In our study, the mean time to full oral feeds was $(7.50 \pm 2.71)$ hours in the cases reduced laparoscopically. It was significantly longer in the cases that had upfront laparotomy due to peritonitis (40.00 \pm 6.93 ) hours. Among the four cases converted to open approach after initial laparoscopic trial, the three cases that needed resection had mean time to full oral feeds $(30.00 \pm 21.63)$ hours and the $4^{\text {th }}$ one was reduced manually with time to full feeds of 48 hours because there was a suspicious ischemic band with abdominal distension and delayed tolerance to oral feeding.

In a study comparing cases managed via open and laparoscopic approach by Hill et al., in 2015 [7], the median time to full feeds was 1 day, (with a range of 0-14 days), and 2 days, (with a range of 1-4 days), for the laparoscopic and laparotomy groups, respectively $(p=0.001)$. In a review of literature, start of oral feeding was established in all laparoscopically reduced series earlier than laparotomy cases [17].

We report a significant shorter hospital stay in favor laparoscopic reduction. In our study the cases that were responded to hydrostatic reduction were discharged the next day with mean hospital stay (1.56 \pm 1.08 day). The cases that managed by laparoscopic intervention and successfully reduced, stayed in the hospital (1-2) days with mean (1.64 \pm $0.50)$ while the cases that underwent urgent laparotomy stayed in the hospital (3-4) days with mean (3.33 \pm 0.58$)$. Mean duration for hospital stay in the cases that converted to laparotomy with bowel resection was $(2.67 \pm 1.53)$ while the case that converted to laparotomy and manually reduced was kept in the hospital for four days because of the presence of suspicious band and delayed start of oral feeding.

In Hill et al., [7] study in 2015; the median length of post-operative hospital stay was 1 day, with a range of 1-15 days, for the LAP group and 3 days, with a range of 1-6 days, for the OPEN group ( $p=0.001)$. Houben et al., in 2016 [18] reported similar results. They described in the study of patients with completed laparoscopic reduction (n $=24$ ) a median hospital stay of 5 (range 3-51) days. The remaining group of individuals $(n=20)$, who had direct open surgery or conversion of laparoscopic approach, remained in hospital 8 (range 314) days.

In our study, 4 cases (25\%) failed to be reduced laparoscopically and were converted to open approach. One of them was successfully reduced by manual reduction and the other three cases needed bowel resection. To our mind, this finding indicates feasibility of laparoscopy in reduction of intussusception as converted cases had gangrenous bowel 
and reduction was completed even during laparoscopy.

Houben et al., in 2016 [18] reported a conversion rate from a laparoscopic approach to an open intervention of $35 \%$. In a study conducted by Bonnard et al., in 2008 [19] on sixty-nine patients, 21 patients required conversion to open surgery (31.9\%). Eleven of these were converted because of failure of laparoscopic reduction, (4) pathologic lead point, (4) bowel ischemia and/or necrosis, (1) perforation and (1) intolerance of pneumoperitoneum.

In the current study, no major intraoperative complications or difficulties such as bowel or vascular injury, decreased venous return, hypercapnia, acidosis were recorded. Minor postoperative complications were documented as two patients (3.4\%) showed postoperative wound infection. Two cases showed wound dehiscence $(3.4 \%)$ both in our open group. One case developed port site hernia $(1.7 \%)$ in the cases that were completed laparoscopically.

Series complications in six cases $(14 \%)$ were noted in another study: Three adhesive intestinal obstructions 9-18 months post-operatively, of which, two obstructions occurred following direct open surgery, and one obstruction was observed after a laparoscopic conversion. Furthermore, one abdominal abscess and one umbilical granuloma. One death was recorded as a result of an uncontrollable sepsis post-hemicolectomy [18]. In a study of Apelt et al., in 2013 [17], they recorded only one intraoperative complication which was a case of iatrogenic visceral perforation $(0.4 \%)$. Postoperative complications were reported in the LAP Group; one of which suffered a post-operative intestinal perforation; it is unclear from the data whether this corresponded to a missed intraoperative perforation or represented a separate event. Also there were two cases of post-operative wound infection and one case of port site hernia. Bonnard et al., in 2008 [19], reported intestinal perforation at postoperative day 9 in a case of HSP reduced laparoscopically.

After a mean follow-up period of six months, there were no detected cases of recurrence in either laparoscopic or open approaches.

\section{Conclusion:}

Despite the short duration of follow-up for most of the patients, laparoscopic reduction of idiopathic intussusception is safe, feasible and provides minimally invasive approach with significantly early oral feeding and reduced hospital stay in skilled hands.

Shorter duration of symptoms significantly improves the success rate of reduction either by enema or laparoscopically.

\section{Conflicts of interest:}

No conflict of interest has been declared.

Authors' contributions:

All authors had equal role in design, work, statistical analysis and manuscript writing.

\section{References}

1- JEN H.C. and SHEW S.B.: The impact of hospital type and experience on the operative utilization in pediatric intussusception: A nationwide study. J. Pediatr. Surg., 44: 241-6, 2009.

2- WAN W.H., LEE J.L., CLARKE M.J., et al.: Diagnosis and laparoscopic management of adult intussusception. ANZ J. Surg., 79: 294-5, 2009.

3- DANEMAN A. and NAVARRO O.: Intussusception Part 2: An update on the evolution of management. Pediatr. Radiol., 34: 97-108, 2004.

4- APPLEGATE K.E.: Intussusception in Children: Imaging Choices. Semin. Roentgenol., 43: 15-21, 2008.

5- BALACHANDRAN B., SINGHI S. and LAL S.: Emergency management of acute abdomen in children. Indian J. Pediatr., 80 (3): 226-34, 2013.

6- GRANT H.W., PARKER M.C., WILSON M.S., et al.: Adhesions after abdominal surgery in children. J. Pediatr. Surg., 43: 152-7, 2008.

7- HILL S.J., KOONTZ C.S., LANGNESS S.M., et al.: Laparoscopic versus open reduction of intussusception in children: Experience over a decade. J. Laparoendosc. Adv. Surg. Tech. A., 23: 166-9, 2013.

8- PONSKY T.A. and ROTHENBERG S.S.: Minimally invasive surgery in infants less than $5 \mathrm{~kg}$ : Experience of 649 cases. Surg. Endosc., 22: 2214-19, 2008.

9- BURJONRAPPA S.C.: Laparoscopic reduction of intussusception: An evolving therapeutic option. J.S.L.S., 11: 235-7, 2007.

10- DUPREE H.J., SENAGORE A.J., DELANEY C.P., et al.: Does means of access affect the incidence of small bowel obstruction and ventral hernia after bowel resection? Laparoscopy versus laparotomy. Am. Coll. Surg., 197: 177-81, 2003.

11- KARIC S.M.: Adhesions and adhesiolysis: The role of laparoscopy. J.S.L.S., 6: 99-109, 2002.

12- PODDOUBNYI I.V., DRONOV A.F., BLINNIKOV O.I., et al.: Laparoscopy in the treatment of intussusception in children. J. Pediatric. Surg., 33: 1194-7, 1998.

13- VAN DER LAAN M., BAX N.M., VAN DER ZEE D.C., et al.: The role of laparoscopy in the management of childhood intussusception. Surg. Endosc., 15: 373-6, 2001. 
14- DANEMAN A. and ALTON D.J.: Intussusception: Issues and controversies related to diagnosis and reduction. Radiol. Clin. North Am., 34: 743-56, 1996.

15- KHORANA J., SINGHAVEJSAKUL J., UKARAPOL N., et al.: Enema reduction of intussusception: The success rate of hydrostatic and pneumatic reduction. Ther. Clin. Risk Manag., 11: 1837-42, 2015.

16- CHEUNG S.T., LEE K.H., YEUNG T.H., et al.: Minimally invasive approach in the management of childhood intussusceptions. A.N.Z. J. Surg., 77: 778-81, 2007.

17- APELT N., FEATHERSTONE N. and GIULIANI S.: Laparoscopic treatment of intussusception in children: A systematic review. J. Pediatr. Surg., 48: 1789-93, 2013.

18- HOUBEN C.H., FENG X.N., TANG S.H., et al.: What is the role of laparoscopic surgery in intussusception? A.N.Z. J. Surg., 86 (6): 504-8, 2016.

19- BONNARD A., DEMARCHE M., DIMITRIU C., et al.: Indications for laparoscopy in the management of intussusception. A multicenter retrospective study conducted by the French Study Group for Pediatric Laparoscooy (GECI). J. Pediatr. Surg., 43: 1249-53, 2008.

20- WEI C.H., FU Y.W., WANG N.L., et al.: Laparoscopy versus open surgery for idiopathic intussusception in children. Surg. Endosc., 29: 668-72, 2015.

21- SKLAR C.M., CHAN E. and NASR A.: Laparoscopic versus open reduction of intussusceptions in children: A retrospective review and meta-analysis. J. Laparoendosc. Adv. Surg. Tech. A., 24: 518-22, 2014.

22- PUJAR V.C. and JOSHI S.: Role of laparoscopy in the management of intussusceptions in children. J. Sci. Soc., 40: 25-7, 2013.

23- CHANG Y.T., LEE J.Y., CHION C.S., et al.: Early laparoscopy for ileocolic intussusceptions with multiple recurrences in children. Surg. Endosco., 23: 2001-4, 2009.

24- ANAND R.J., SHAH S.R. and KANE T.D.: Laparoscopic management of delayed recurrent intussusception in an older child. J.S.L.S., 11: 106-8, 2007.

25- TEITELBAUM D.H., KIA K.F., VIDYA K., et al.: Laparoscopic vs open surgical approach for intussusceptions requiring operative intervention. J. Pediatr. Surg., 40: 281-4, 2005.

26- BOEHM R. and TILL H.: Recurrent intussusceptions in an infant that were terminated by laparoscopic ileocolonic pexie. Surg. Endosc., 17: 831-2, 2003.

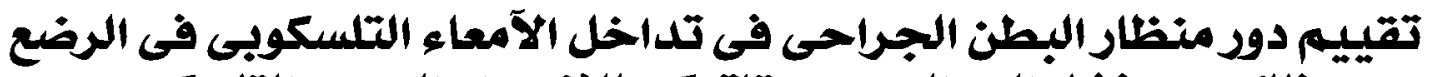

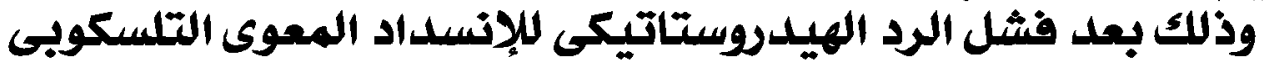

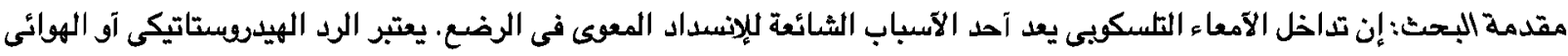

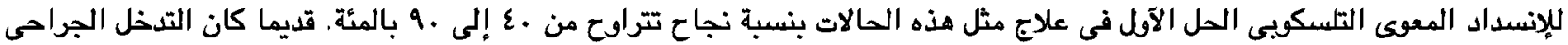

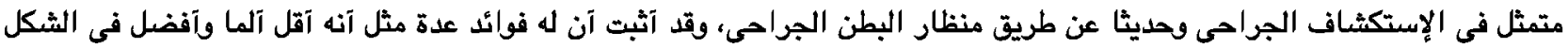

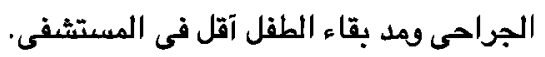 \\ الهدف من البحث: تقييم دو منظار البطن الجراحى فى تداخل الآمعاء التلسكوبى فى الرضع وذلك بعد فشل الرد الهيدوستاتيكى للإنسداد

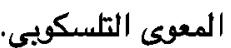 \\ المرضى وطرق البحث: تم عمل دراسة على حالات الإنسداد المعوى التلسكوبى فى الرضع بوحدة جراحة الآطفال بمستشفى طنطا

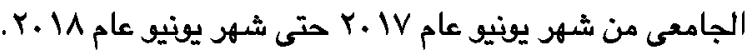

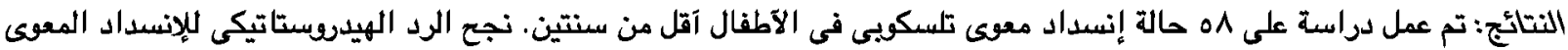

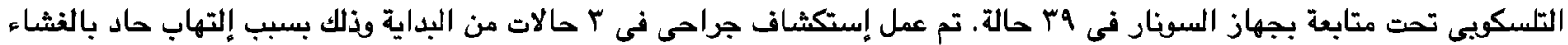

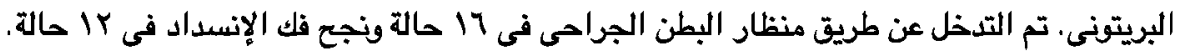

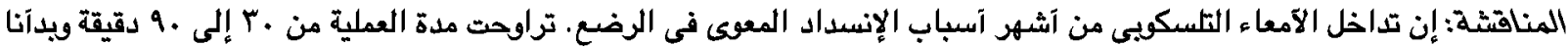

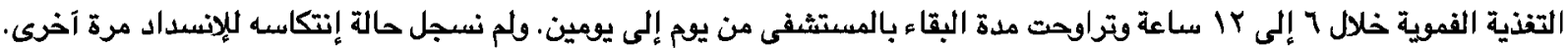 \\ الإستتاجات: لقد ثبت آن منظار البطن الجراحى يقتبر حل آمن وكفء فى علاج إنسداد الآمعاء التلسكوبى بشرط توافر الخبرة الكافية \\ في إستخدام منظار البطن الجراحى. إستخدام المنظار يسرع من بداً التغذية بالفم ويقلل الإقامة بالمستشفى.
}

